\title{
Performance Financeira de Aeroportos Concedidos de um País Hipotético
}

\author{
Financial Performance of Airports Granted in a Hypothetical Country
}

\author{
Carlos Henrique Rocha ${ }^{1}$ \\ Paulo Augusto P. de Britto ${ }^{2}$
}

\begin{abstract}
Resumo
Este caso de ensino possibilita aos estudantes do curso de graduação em Administração entender o funcionamento prático da definição de lucro anual uniforme e de dois conceitos derivados dele. $O$ primeiro é o cálculo do superávit ou déficit acumulado em uma data futura de um projeto, e o outro é o cômputo da necessidade futura de caixa entre dois anos de execução do projeto. $O$ caso deve ser utilizado como material didático suplementar nas disciplinas de Engenharia Econômica, Avaliação Econômica de Projetos, Avaliação de Projetos de Investimentos, ou disciplinas afins. É requerido que os estudantes tenham conhecimentos de matemática financeira e conheçam o conceito de lucro anual uniforme. O estudo de caso diz respeito a dois aeroportos concedidos no último dia útil de dezembro de 2013 de um país fictício, sendo um localizado na capital do país e o outro, no Sul do país. $O$ quadro financeiro dos dois aeroportos era desfavorável. O diretor Fernandez da agência reguladora desse país pediu para um especialista em regulação da agência que avaliasse o déficit acumulado dos aeroportos em 2018 e a necessidade de caixa extra de 2019 até o vencimento dos contratos de concessão. O especialista Marcus R. Fortes concluiu que o déficit do aeroporto da capital, em 2018, é de $\$ 349,1$ milhões e a necessidade adicional de caixa é de $\$ 16$ milhões/ano. O saldo negativo do aeroporto do Sul, em 2018, é de $\$ 96$ milhões e a necessidade extra de caixa é de $\$ 4,4$ milhões/ano.
\end{abstract}

Palavras-chave: lucro anual uniforme. valor futuro. valores presente e futuro anualizados. saldo devedor. necessidade de caixa.

\begin{abstract}
This teaching case enables undergraduate Business Administration students to understand the practical functioning of the definition of uniform annual profit and two concepts derived from it. The first is the calculation of the surplus or deficit accumulated at a future date of a project, and the other is the calculation of the future need for cash between two years of project execution. The case should be used as supplementary teaching material in the disciplines of Economic Engineering, Economic Evaluation of Projects, Evaluation of Investment Projects, or similar disciplines. Students are required to know about financial mathematics and the concept of uniform annual profit. The case study concerns two airports granted on the last business day of December 2013 in a fictitious country, one located in the country's capital, and the other one in the south of the country. The financial situation of the two airports was unfavorable. Director Fernandez of the country's regulatory agency asked an agency regulation expert to assess the airport's accumulated deficit in 2018 and the need for extra cash from 2019 until the expiration of the concession contracts. Specialist Marcus $R$. Fortes concluded that the capital airport's deficit in 2018 is \$ 349.1 million, and the additional cash requirement is \$16 million / year. The negative balance for the South airport in 2018 is $\$ 96$ million, and the extra cash requirement is $\$ 4.4$ million / year.
\end{abstract}

Keywords: uniform annual profit. future value. annualized present and future values. debit balance. need for cash.

\section{Introdução}

Em todo o mundo tem havido privatizações de aeroportos comerciais desde o fim da década dos anos 90 , com destaque para o Reino Unido, que se notabilizou como precursor (GRAHAM, 2011). Estima-se que cerca de quinhentos aeroportos comerciais em todo o mundo foram totalmente ou parcialmente privatizados até 2016 (GUPTA, 2015). 
O número de passageiros transportados por avião aumentou fortemente em todo o mundo, passando de 1,57 bilhão em 1990 para 3,3 bilhões em 2014. Estudos feitos em 2015 preveem que, em 2034, a movimentação mundial de passageiros nos aeroportos atinja 7,3 bilhões (BEZERRA; GOMES, 2016).

O Brasil inaugurou as privatizações de aeroportos em 2011, com o aeroporto de São Gonçalo do Amarante, município próximo a Natal, capital do Rio Grande do Norte, doravante aeroporto de Natal (PEREIRA; ROCHA, 2019). O modelo de privatização adotado pelo governo brasileiro foi o de concessão, em que a iniciativa privada constrói, opera durante um período predefinido e devolve o aeroporto para o domínio do Estado após esse período. Hoje, são vinte e dois aeroportos concedidos (PEREIRA; ROCHA, 2019).

Os aeroportos brasileiros são leiloados na Bolsa de Valores, Mercadorias e Futuros de São Paulo, atual Brasil Bolsa Balcão (B3). As concessões pagam pelo direito de operar os aeroportos, assim também é em muitos países (GUPTA, 2015). O governo brasileiro estabelece, por meio de estudo de viabilidade econômica, o valor mínimo do certame. No início do leilão, os interessados apresentam as suas propostas em envelopes fechados, e as três maiores disputam na bolsa um leilão do tipo inglês, em que o maior lance vence o leilão.

As desestatizações aeroportuárias brasileiras foram motivadas, essencialmente: (a) pela necessidade de ampliar e modernizar as infraestruturas e, assim, manter os padrões internacionais de qualidade nos aeroportos, (b) pela escassez de recursos governamentais para investimento e (c) pela necessidade de aumentar a arrecadação (PEREIRA; ROCHA, 2019). Essas mesmas motivações têm dominado as privatizações de aeroportos ao redor do mundo, destaca Graham (2011). Os aeroportos são intensivos em infraestrutura e exigem uma grande quantidade de investimentos.

Uma concessão, qualquer que seja, é regularmente vista como uma empresa-projeto, que tem começo, meio e fim (FINERTTY, 2013; FLORIN et al, 2017). Assim sendo, conceitos de avaliação de projetos de investimentos podem ser aplicados às concessões.

Este artigo apresenta um caso de ensino para utilização como material de suporte acadêmico nos cursos de graduação em Administração. Em uma situação hipotética, são calculados os déficits acumulados (de 2014 a 2018) de dois aeroportos concedidos e as suas necessidades extras de caixa entre 2019 e o término dos contratos de concessão. A base teórica do estudo está na engenharia econômica (FERREIRA, 2009).

Os dois aeroportos internacionais estudados pertencem a um país fictício. Um aeroporto está localizado na capital do país e o outro, no Sul do país. Ambos foram concedidos nos últimos dias de dezembro de 2013 e por um prazo de trinta anos. Após os investimentos programados, o aeroporto da capital terá capacidade para movimentar, anualmente, cinco milhões de passageiros e o aeroporto do Sul, 3,5 milhões de passageiros por ano. Os investimentos nos aeroportos ocorreram entre 2014 e 2016.

O aeroporto do Sul foi agraciado, em 2017, com o prêmio de melhor serviço prestado aos passageiros entre os aeroportos mundiais na faixa de três a seis milhões de passageiros movimentados por ano. Em 2018, foi a vez do aeroporto da capital. O prêmio avalia a limpeza do terminal, o ambiente do aeroporto, painéis de voos, entre outros quesitos.

\section{Privatizações de aeroportos ao redor do mundo}

Na metade da década dos 1980, passou a existir uma tendência mundial crescente em direção a menos intervenção governamental na economia e maior dependência do setor privado para a prestação de uma variedade de serviços públicos. Essa foi a forma encontrada pelos governos para reduzir a dependência do dinheiro dos impostos e intensificar a sua aplicação nos serviços essenciais para a sociedade (ABDELDAYEM; ALDULAIMI, 2019).

O Reino Unido inaugurou a venda de aeroportos comerciais durante o governo Thatcher, em 1987 (GRAHAM 2011; VASIGH; HARIRIAN, 2003). A antiga British Airports Authority foi integralmente transferida para a iniciativa privada através de leilão, que levantou 2,3 bilhões de dólares (BAIJAL, 2000). O mesmo foi com a Belfast International Airpor,t em 1994, na Irlanda do Norte (JUAN, 1996). O setor privado possui 64\% do capital social do aeroporto de Copenhagen, na Dinamarca. O aeroporto de Viena, na Áustria, foi privatizado em 1992. Investidores privados possuem $42 \%$ do aeroporto de Zurique, na Suíça. O aeroporto de Bruxelas, na Bélgica, foi parcialmente privatizado em 2004, ficando o governo com $30 \%$ do capital social do aeroporto (GILLEN, 2011). Na Polônia, todos os aeroportos são empresas públicas, mas admitem a participação privada (MIECZNIKOWSKI; TŁOCZYŃSKI, 2018). Gupta (2015) nota que, hoje, três em cada quatro passageiros na Europa viajam através de um aeroporto parcial ou totalmente privatizado. O aeroporto internacional de Prishtina, em Kosovo, foi privatizado em 2010. O aeroporto é operado por um consórcio turco e francês. Os turcos possuem cerca de $90 \%$ das ações do aeroporto e o restante pertence aos franceses (FLORIN et al, 2017).

Cinquenta e um por cento do capital social do aeroporto de Auckland, na Nova Zelândia, foi parar nas mãos da iniciativa privada em 1998. O aeroporto de Perth, na Austrália, em 1997, foi concedido por 50 anos por um valor de 639 milhões de dólares australianos. O aeroporto de Sidnei, também na Austrália, em 2002, foi concedido à iniciativa privada por 50 anos e a concessão custou 5,6 bilhões de dólares australianos (AULICH, 2015). A Austrália privatizou também os aeroportos de Brisbane e Melbourne. Eles foram vendidos por AU \$2,7 bilhões (VASIGH \& HARIRIAN, 2003).

O aeroporto Ezeiza, em Buenos Aires, na Argentina, foi concedido por 30 anos em 1999, já se foram 20 anos de concessão. O aeroporto Juan Santamaria, na Costa Rica, foi concedido por 20 anos em 1999. O arranjo garantiu ao governo costarriquenho $40 \%$ da receita anual do aeroporto. O aeroporto de Lima, no Peru, foi concedido por 30 
anos em 2001. O novo aeroporto de Atenas, na Grécia, foi construído pela iniciativa privada em 2001, que cuidará da administração e operação até 2031 (GILLEN, 2011).

O governo americano tentou aderir às concessões aeroportuárias no final de 2007 com o aeroporto de Chicago Midway. A transação não foi adiante por conta da crise financeira mundial de 2008 e, posteriormente, a ideia foi abandonada (Graham, 2011). Em 2013, o aeroporto Luis Munoz Marin, em San Juan, do estado americano de Porto Rico, foi privatizado. Grande parte dos aeroportos americanos pertence a empresas dos governos municipais, assim também é no Canadá (GRAHAM, 2011; POOLE; EDWARDS, 2016).

As concessões aeroportuárias mexicanas começaram em 1988. O governo estratificou os cinquenta e oito aeroportos federais em cinco blocos ou grupos (GALEANA, 2008). A participação privada no aeroporto mexicano é de $15 \%$ do capital social e tem prazo de cinquenta anos, podendo ser renovada por igual período. Para esse propósito, o governo mexicano criou quatro empresas de administração aeroportuária de capital misto (GALEANA, 2008), são elas: Grupo Aeroportuário do Pacífico (GAP), Grupo Aeroportuário do Centro Norte (OMA), Aeroportos do Sudeste do México (ASUR) e Aeroporto Internacional da Cidade do México (AICM). O quinto bloco de aeroportos foi declarado não disponível para participação privada, sendo administrado pelo governo.

Em função de sua topografia acidentada, o avião é o meio de transporte mais usado na Colômbia. Para desonerar o governo colombiano dos gastos para manter e modernizar a infraestrutura aeronáutica, a administração e operação dos seus aeroportos mais movimentados foram para a iniciativa privada por meio de concessão. $O$ primeiro aeroporto concedido foi o de Cartagena das Índias, em 1996, por um prazo de dezessete anos (OLARIAGA; ÁLVAREZ, 2015). Os aeroportos de menor movimentação de passageiros continuaram com o Estado. Hoje, são dezenove aeroportos concedidos (OLARIAGA; MORENO, 2019).

Entre 1988 e 1994, o governo chinês implementou uma profunda reforma na administração de seus principais aeroportos, pari passu com os conceitos de mercado. Nessa época, o governo central transferiu os aeroportos de Xiamen Caoqi e Shanghai Hongqiao para os respectivos governos locais. As reformas continuaram entre $1995 \mathrm{e}$ 2001, momento em que o governo central transferiu outros aeroportos sob sua jurisdição para os governos locais e permitiu a participação de capital privado nos negócios desses aeroportos. As reformas foram intensificadas a partir de 2002 e, com exceção do aeroporto de Pequim e os do Tibete, todos foram entregues para os governos locais. Acrescente-se que as empresas locais de administração aeroportuária passaram a ser de capital misto, aceitando a presença de dinheiro privado na sua composição societária (YANG; TOK; SU, 2008).

É justo registrar que o processo de privatização de aeroportos no continente asiático iniciou na Malásia, considerado o país mais liberal da Ásia (VASIGH \& HARIRIAN, 2003). As concessões foram amplamente utilizadas pelo governo malaio para o desenvolvimento de novas infraestruturas aeroportuárias e operação em troca de um pagamento inicial e de outros pagamentos regulares a título de arrendamento ou outorga (HOOPER, 2002).

Até 2017, havia seis aeroportos concedidos na Índia. A Tailândia transformou a sua empresa de autoridade aeroportuária em sociedade de economia mista, aceitando a participação de capital privado, como foi na Polônia. Essa foi a maneira que o governo tailandês encontrou para modernizar seus aeroportos (GUPTA, 2015).

Existem casos em que os governos permitem aos privados a construção e ampliação de terminais nas áreas dos aeroportos e a conseguinte exploração deles por tempo limitado, como no aeroporto de Toronto, no Canadá, e no aeroporto Daniel Oduber Quirós, na Costa Rica (GUPTA, 2015; VASIGH; HARIRIAN, 2003).

O movimento global de privatizações promoveu o surgimento de empresas mundiais de administração e operação de aeroportos (FORSYTH; NIEMEIER; WOLF, 2011), como:

\begin{tabular}{lc}
\hline \multicolumn{1}{c}{ Empresa } & País \\
\hline AENA Desarrollo Internacional SME S/A ${ }^{1}$ & Espanha \\
Changi Airports International & Singapura \\
Fraport AG Frankfurt Airport Services & Alemanha \\
Suíça Zurich International Airport & Suíça \\
Vinci Airports $^{2}$ & França \\
\hline
\end{tabular}

${ }^{1}$ Possui a maior carteira de aeroportos espalhados pelo mundo. ${ }^{2} E$ a segunda maior empresa aeroportuária mundial, operando em quase todo o mundo.

No Brasil, a gestão dos principais aeroportos ficava por conta da empresa pública Infraero, que, em 2010, administrava 67 aeroportos, os quais representavam 97\% do tráfego aéreo regular brasileiro (COSTA et al, 2017; RIBEIRO; FIORAVANTI; CRUVINEL, 2018). Até que, em 2011, o Brasil embarcou na esteira da desestatização de aeroportos. Como mencionado antes, o modelo adotado foi o de concessão, em que a iniciativa privada constrói, opera durante um período predefinido e devolve o aeroporto para o domínio do governo após esse período. AAgência Nacional de Aviação Civil é a responsável pelas concessões aeroportuárias. 
O primeiro aeroporto brasileiro concedido foi o de São Gonçalo do Amarante, no Rio Grande do Norte (aeroporto de Natal), em 2011. Depois, em 2012, foram concedidos os aeroportos de Brasília, no Distrito Federal, e Guarulhos e Viracopos, em São Paulo. Na $3^{\text {a }}$ rodada, foram concedidos os aeroportos do Galeão, no Rio de Janeiro e Confins, em Minas Gerais. Em março de 2019, foi realizada a $5^{\text {a }}$ rodada de concessão, somando vinte e dois aeroportos nas mãos da iniciativa privada. Nove deles estão na Região Nordeste, seis no Sudeste, cinco no Centro-Oeste e dois na Região Sul.

O que se pode dizer é que o papel do Estado brasileiro mudou de proprietário para regulador e formulador de políticas para o setor aéreo, sendo que as responsabilidades operacionais, de investimento e de gestão dos aeroportos passaram para a iniciativa privada. Convém dizer que o papel do governo como regulador econômico é especialmente importante à luz do fato de que os aeroportos tendem a serem monopólios naturais.

\section{0 aeroporto dos tempos atuais}

Em termos modernos, um aeroporto funciona como uma firma multiprodutos e, de modo geral, possui dois tipos de negócio: um associado ao mercado do ar, como companhias aéreas de passageiros e de cargas, operadores aeroportuários e passageiros, e outro desvinculado do ar, como locatários comerciais e empresas de planejamento de embarque e desembarque de passageiros (GILLEN, 2011; JONES; DUNSE, 2015).

Portanto, os aeroportos são remunerados por meio de receitas tarifárias e não tarifárias. As primeiras receitas são compostas pela tarifa de embarque, de conexão, de pouso, de permanência no solo, de armazenagem e tarifa de capatazia. Essas receitas dependem do número de passageiros, do número de aeronaves em trânsito, do tempo de permanência em solo e do volume de carga processada nos aeroportos (PEREIRA; ROCHA, 2019).

A receita não tarifária é apurada por intermédio do arrendamento de áreas comerciais (aluguéis), que possibilitam a exploração do sítio aeroportuário com a venda de bens e serviços, com a instalação de shoppings, hotéis e parques de estacionamentos. Esse tipo de receita fornece um razoável grau de atratividade para o empreendimento aeroportuário, representando, em média, $35 \%$ das receitas totais da concessão nos aeroportos mundiais, destacam Battal e Bakir (2017). Nos aeroportos europeus, em particular, as receitas dos negócios não vinculadas à aviação representam, em média, 44\% do total das receitas (JONES; DUNSE, 2015).

As receitas não aeroportuárias ajudam a servir a manutenção do aeroporto e a realizar investimentos na infraestrutura, o que justifica as estratégias implantadas para tal fim, como: aumento do espaço comercial nos terminais dos aeroportos, políticas de marketing e preços adotados a partir do perfil dos passageiros, monitoramento do comportamento de compras dos usuários e facilidades diversas para a realização de conexões de voos (PEREIRA; ROCHA, 2019).

É óbvio que os métodos de valoração dos aeroportos para efeito de privatização tomam em conta as receitas tarifárias e não tarifárias na construção dos fluxos anuais de caixa (FLORIN et al, 2017; VASIGH; OWENS; YOO, 2003).

\section{O ESTUDO DE CASO}

\subsection{Resumo do caso}

Este caso de ensino mostra a aplicação do conceito de lucro anual uniforme. Em geral, os estudantes encontram dificuldades com esse conceito, porque demoram a entender que as receitas e custos de operação e manutenção estão avaliados em termos anuais, já os custos de investimento e o valor residual, se houver, precisam ser anualizados, isto é, eles devem ser colocados na mesma base de comparação das receitas e dos custos operacionais. Usa-se o fator de $\mathrm{P}$ (valor presente) para A (valor anualizado) da matemática financeira para anualizar os custos de investimento, ao passo que se emprega o fator de $\mathrm{F}$ (valor futuro) para A para anualizar o valor residual. Se houver investimentos além do ano zero, deve-se, primeiro, trazê-los para valor presente, antes da anualização.

O estudo de caso lida com concessões aeroportuárias de um país fictício. O país concedeu aos privados seus dois aeroportos internacionais por trinta anos: um localizado na capital e outro, no Sul do país.

A pedido do diretor da agência reguladora das infraestruturas de transporte, o especialista em regulação Marcus R. Fortes elaborou uma nota técnica que discorre sobre: (a) desequilíbrio financeiro acumulado de cada aeroporto concedido entre 2014 e 2018 e (b) a necessidade adicional de caixa de cada aeroporto de 2019 até o fim da concessão. No país de Marcus R. Fortes não havia inflação; todos se orgulhavam disso.

\subsection{Aplicação do caso}

O caso deve ser utilizado como material didático suplementar nas disciplinas de Engenharia Econômica, Avaliação Econômica de Projetos, Avaliação de Projetos de Investimentos, ou disciplinas afins. É indispensável que os estudantes tenham conhecimentos de matemática financeira e conheçam o conceito de lucro anual uniforme. 


\subsection{Fontes dos dados}

Os dados financeiros referentes aos aeroportos foram criados pelos autores do artigo, ou seja, os dados são hipotéticos.

\subsection{Objetivos educacionais}

Os objetivos educacionais deste caso são:

a) Exemplificar o emprego prático do conceito de lucro anual uniforme.

b) Mostrar como se pode obter a necessidade anual futura de caixa de um projeto de investimento ou de uma empresa-projeto por meio da aplicação prática dos conceitos de valor futuro, valor presente e valor anualizado.

\subsection{0 caso em si}

Nos últimos dias de dezembro de 2013, na esteira do Reino Unido e de tantos outros países, inclusive o Brasil, o governo de um pequeno país em algum lugar do mundo concedeu à iniciativa privada seus dois aeroportos internacionais, sendo um localizado na capital e o outro, na Região Sul do país. O objetivo do governo era se desonerar dessas infraestruturas. O governo tinha outras prioridades com os recursos dos impostos. O modelo de leilão adotado se assemelha ao brasileiro. O órgão regulador recebe o nome de Agência Federal de Infraestruturas de Transportes (AFIT). Permite-se que o aeroporto, a qualquer época, em estado de insolvência, peça relicitação (devolução amigável do aeroporto para o Estado).

O aeroporto da capital foi arrematado por uma empresa alemã de gestão e operação aeroportuária por $\$ 3,8$ bilhões, 2,5 vezes maior que o valor mínimo de leilão. O aeroporto do Sul foi comprado por uma empresa espanhola por $\$ 1,8$ bilhão. A maioria de seus passageiros é turista, vindos de todas as partes do mundo para surfar as ondas quase que perfeitas das praias do Sul. O prazo de concessão de ambos os aeroportos é de 30 anos, expirando no fim de 2043, e os dois estão listados na bolsa local. O aeroporto da capital vendeu ações ordinárias e debêntures (obrigações) e o do Sul somente ações ordinárias. O modelo de governança adotado pelos dois aeroportos dá primazia aos interesses dos acionistas, como em Jensen (2001).

Era 13 de agosto de 2019, uma sexta-feira, quando o diretor técnico da agência, Sebastian Fernandez, pediu à sua secretária Arminda para que chamasse um especialista em regulação do quadro permanente da AFIT. Por motivos ainda desconhecidos, Arminda chamou o especialista em regulação de infraestruturas de transportes Marcus R. Fortes.

Em minutos, lá estava o rapaz, na sala da secretária do diretor. Logo ela o anunciou. Marcus pediu licença e entrou, às suas costas ouviu a porta do gabinete se fechar. $O$ diretor Fernandez não tinha ainda 50 anos, mas aparentava muito mais. Fernandez aguardava Marcus sentado atrás de sua generosa mesa de mármore.

- Sente-se, meu caro! - disse o diretor, completando - Qual o seu nome?

- Marcus R. Fortes, senhor! - respondeu o especialista.

- R.? - questionou o diretor.

- R. de Régulateur, senhor! Nome de origem francesa.

O diretor conteve o riso.

- Qual a sua formação rapaz?

- Sou graduado em Administração e mestre em Finanças Corporativas. Mas, logo após concluir a graduação, ingressei no Exército como militar temporário, senhor! Deixei o Exército quando tomei posse na Agência, senhor! Quando cursei o mestrado, eu já estava na AFIT, senhor!

- Muito bem - disse o diretor. - Me diga, rapaz, você sabe que os nossos dois aeroportos concedidos não estão bem financeiramente? A rentabilidade anual dos aeroportos tem sido negativa.

- Sim, tenho acompanhado, senhor!

- Pois então, gostaria de conhecer o tamanho do desequilíbrio financeiro dos aeroportos e a necessidade anual adicional futura de dinheiro dos dois aeroportos daqui em diante, até o vencimento da concessão.

- Quanto tempo eu tenho, senhor?

- Não muito, final de outubro.

- Última questão, senhor! Existe valor de reversibilidade dos investimentos feitos nos aeroportos?

- Não, disse o diretor, encerrando a reunião.

Marcus meneou a cabeça, aceitando a empreitada! O diretor não revelou o que faria com os resultados da análise de Marcus, tampouco Marcus o indagou.

$\mathrm{Na}$ verdade, a nota técnica elaborada por Marcus R. Fortes não traz nada de novo, porém o seu mérito foi reunir conceitos econômico-financeiros para responder aos questionamentos feitos pelo diretor da Agência. 
Nota Técnica AFIT No 10/2019, de 18 de outubro de 2019

Esta Nota Técnica estabelece a forma de cálculo do equilíbrio (e desequilíbrio) financeiro de um aeroporto concedido. A fundamentação teórica está na Engenharia Econômica (FERREIRA, 2009). Admite-se que o aeroporto concedido seja uma empresa-projeto, com começo, meio e fim.

\section{Equilíbrio financeiro do aeroporto concedido e necessidade adicional anual futura de caixa}

A equação básica da análise é a fórmula do lucro anual uniforme ( $L A U)$, que pode ser representada, para o caso de um aeroporto, assim:

(1)

$$
L A U=(R-C)-(I+A) \times \frac{(1+r)^{n} \times r}{(1+r)^{n}-1}
$$

Em que $R$ é a receita total por ano, $C$ é o custo total anual, exceto o custo de investimento, lé o valor presente do custo do investimento, $A$ é o valor de aquisição do aeroporto, $r$ é a taxa mínima de atratividade estabelecida pelo governo e $n$ é o horizonte temporal do projeto. A segunda parcela do lado direito da equação (1) será chamada, daqui para frente, de $I A$.

Se o projeto de investimento apresentar valor residual, ele também deve ser anualizado, conforme a equação (2), e deve aparecer no lado direito da equação (1) com sinal positivo, pois representa uma receita:

$$
V R a=V R_{n} \times \frac{r}{(1+r)^{n}-1}
$$

Em que $V R a$ é o valor residual anualizado e $V R_{n}$ é o valor residual no futuro $n$. $O$ valor de reversibilidade, no caso de concessões de infraestrutura de transportes, se assemelha ao valor residual.

$O$ resultado financeiro do aeroporto concedido $k$, no ano $t, S_{k t}(L A U)$, pode ser simbolizado da seguinte maneira:

$$
S_{k t}=(R-C)_{k t}-I A_{k}
$$

Note-se que a variável $S_{w t}$ pode assumir valores positivos ou negativos. $S e S_{k t}$ for igual a zero, diz-se que o aeroporto, nesse caso, está com suas as contas equilibradas. $O$ aeroporto seria remunerado somente pela taxa mínima de atratividade.

O resultado financeiro acumulado do aeroporto $k$, de 2014 a 2018, pode ser calculado de acordo com a equação (4), considerando $t=1$ (2014), $t=2(2015), \ldots, t=5$ (2018):

$$
\begin{aligned}
& S A_{k 2018}=S_{k 5}+S_{k 4} \times(1+i)+S_{k 3} \times(1+i)^{2} \\
& +S_{k 2} \times(1+i)^{3}+S_{k 1} \times(1+i)^{4}
\end{aligned}
$$

Em que $i$ é a taxa de correção (atualização) monetária.

A necessidade anual de caixa adicional do aeroporto $k$, daqui para frente e até o final da concessão, é calculada da seguinte forma:

$$
\left\{\begin{array}{l}
\text { se } i>0, N A C_{k}=S A_{k T} \times \frac{i \times(1+i)^{m}}{(1+i)^{m}-1} \\
\text { se } i=0, N A C_{k}=\frac{S A_{k T}}{m}
\end{array}\right.
$$

Na equação (5), $m$ é o número de anos restantes de concessão de 2019 para frente. Se o resultado financeiro acumulado do aeroporto $k$ for negativo (positivo), então $N A C_{k}>0(<0)$.

Esta nota técnica tem dois apêndices. O primeiro apêndice traz informações básicas dos aeroportos da capital e do Sul. O segundo apêndice apresenta os resultados referentes aos desequilíbrios financeiros dos dois aeroportos e as respectivas necessidades adicionais anuais futuras de caixa.

À consideração superior.

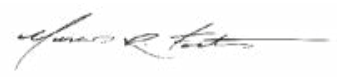

Marcus R. Fortes

Especialista em Regulação de Infraestruturas de Transportes

Em suma, no dia 22 de outubro, precisamente às 10 horas, o especialista Marcus R. Fortes, acompanhado do seu chefe imediato, encontrava-se no gabinete do diretor Fernandez apresentando os resultados de seu estudo sobre as finanças dos dois aeroportos concedidos. A reunião encerrou por volta das 12 horas.

$\mathrm{O}$ diretor Fernandez ficou satisfeito com o resultado do trabalho de Marcus, parabenizando, inclusive, o seu chefe imediato, Dr. Jornada. 
Inesperadamente, o diretor Fernandez revelou que pretende apresentar o estudo de Marcus na próxima reunião da diretoria da Agência. Ele informou também que solicitou ao Departamento Jurídico um parecer justificando uma possível renegociação do valor de outorga. O diretor desconfia que os aeroportos pedirão, em breve, relicitação.

\subsection{Questões para discussão}

As questões para discussão são exatamente aquelas feitas pelo diretor da AFIT ao especialista em regulação Marcus R. Fortes. São elas:

a) Qual o tamanho do desequilíbrio financeiro acumulado em 2018 por cada aeroporto concedido?

b) Qual a necessidade adicional futura de caixa de cada aeroporto concedido de 2019 até o fim da concessão?

\section{Discussão}

Para responder aos dois questionamentos é necessário reunir informações básicas dos aeroportos da capital e do Sul do país, conforme apresentado na Tabela 1. O aeroporto da capital foi comprado por mais de 2,5 vezes o seu valor mínimo de leilão. O aeroporto do Sul comprometeu-se a pagar para o governo, a título de outorga, a quantia de \$142 milhões por ano durante trinta anos, considerando a taxa mínima de atratividade de $6,81 \%$ ao ano. O aeroporto da capital foi comprado por mais de duas vezes o valor do aeroporto da Região Sul.

Os resultados financeiros realizados para os anos de 2014 a 2018 e o investimento requerido anualizado mais o valor de aquisição anualizado, para uma taxa de juros de 6,81\% ao ano, dos aeroportos estão apresentados na

Tabela 1 - Informações básicas dos aeroportos da capital e do Sul

\begin{tabular}{cccccc}
\hline Aeroporto & Valor mínimo $(\mathbf{A})$ & Valor de aquisição $(\mathbf{B})$ & Investimento & Prazo de concessão (ano) & B/A \\
\hline Capital & $\$ 1,5$ bilhão & $\$ 3,8$ bilhões & $\$ 2,6$ bilhões & 30 & 2,53 \\
Sul & $\$ 1,1$ bilhão & $\$ 1,8$ bilhão & $\$ 2,4$ bilhões & 30 & 1,64 \\
\hline
\end{tabular}

Fonte: Site da AFIT.

Tabela 2. Como pode ser visto, os aeroportos apresentaram desequilíbrio financeiro durante todo o período 20142018, conforme definido pela equação (3) da Nota Técnica AFIT No 10/2019, de 18 de outubro de 2019. O fluxo de caixa disponível realizado representa a primeira parcela do lado direito da equação (3). Merece comentário o resultado financeiro do aeroporto do Sul em 2018. A queda no fluxo de caixa foi devida, principalmente, ao derramamento de petróleo cru no mar, atingindo as praias da região e, assim, reduzindo sobremaneira o turismo de surf. Em 2017, o país foi sede do campeonato mundial de surf para não profissionais. O reflexo disso foi um ligeiro aumento nos fluxos de caixa dos aeroportos.

O especialista Marcus R. Fortes usou as informações apresentadas nas Tabelas 1 e 2 para calcular o desequilíbrio acumulado entre 2014 e 2018 por cada aeroporto, bem como para apurar a necessidade adicional de caixa de 2019 até o fim do prazo de concessão. Lembrando que os dados são hipotéticos.

Tabela 2 - Investimento e outorga anualizados para os aeroportos e os respectivos resultados financeiros anuais realizados (2014-2018)

\begin{tabular}{lcccccc}
\hline Aeroporto & IA & \multicolumn{5}{c}{ Fluxo de caixa disponível realizado+ $(\$$ mil $)$} \\
\cline { 3 - 7 } & $(\$ \mathrm{mil})$ & 2014 & 2015 & 2016 & 2017 & 2018 \\
\hline Capital & 505.944 & 404.000 & 430.383 & 420.921 & 428.520 & 496.763 \\
Sul & 332.026 & 300.898 & 311.776 & 318.336 & 342.867 & 290.248 \\
\hline
\end{tabular}

A = investimento requerido anualizado mais o valor de aquisição anualizado. ${ }^{1}$ Livre de juros e amortização de empréstimos para a realização do investimento planejado e da parcela anual referente à compra pelo direito de operar o aeroporto. Fonte: Os fluxos de caixa realizados dos aeroportos foram obtidos dos demonstrativos financeiros dos aeroportos publicados no site da AFIT.

A Tabela 3 mostra o saldo devedor avaliado no final de 2018 para os dois aeroportos estudados e a necessidade anual adicional de caixa futura de cada um deles. O aeroporto da capital necessitará faturar, adicionalmente, $\$$ 16 milhões por ano para manter suas contas equilibradas daqui em diante até o vencimento da concessão. $O$ aeroporto do Sul encontra-se em melhor situação financeira, sendo a sua necessidade adicional de recursos até o fim da concessão de $\$ 4,4$ milhões/ano. 
Tabela 3 - Saldo devedor acumulado e a necessidade anual de caixa dos aeroportos da capital e da Região Sul

\begin{tabular}{ccc}
\hline Aeroporto & Saldo acumulado em 2018 (\$ mil) & Necessidade anual de caixa adicional até o vencimento $\mathbf{( \$ ~ m i l ) ~}$ \\
\hline Capital & -349.133 & 15.853 \\
Sul & -96.005 & 4.359 \\
\hline
\end{tabular}

É importante mencionar que, para calcular o saldo acumulado em 2018 (Tabela 3), a correção monetária foi nula (a inflação no país é zero). Por outro lado, usou-se $1 \%$ ao ano para a atualização monetária na conta da necessidade anual de caixa adicional. O Banco Central admite que o país enfrentará uma onda de inflação por alguns longos anos.

Em complemento, Marcus R. Fortes preparou a Tabela 4. Os dados dizem respeito à razão entre o fluxo de caixa anual efetivo e IA, multiplicado por 100, segundo o aeroporto e ano. Claramente, o desempenho financeiro do aeroporto do Sul é melhor do que o da capital, embora ambos sejam deficitários. Em 2017, em função do campeonato de surf, o resultado financeiro do aeroporto do Sul foi positivo. A performance do aeroporto da capital foi melhor em 2018 em comparação aos outros anos, porque o país recebeu uma avalanche de congressos científicos, inclusive o XXIII Congresso Mundial de Ensino, Aprendizagem e Novas Tecnologias Educacionais em Administração.

Tabela 4 - Razão entre fluxo de caixa operacional realizado e IA, segundo o aeroporto (2014-2018)

\begin{tabular}{cccccccc}
\hline Aeroporto & $\mathbf{2 0 1 4}$ & $\mathbf{2 0 1 5}$ & $\mathbf{2 0 1 6}$ & $\mathbf{2 0 1 7}$ & $\mathbf{2 0 1 8}$ & Média \\
\hline Capital & 79,85 & 85,07 & 83,20 & 84,70 & 98,19 & 86,20 \\
Sul & 90,62 & 93,90 & 95,88 & 103,27 & 87,42 & 94,22 \\
\hline
\end{tabular}

Marcus R. Fortes observou nos demonstrativos financeiros dos dois aeroportos que a receita não voo representou, em média (2014-2018), 30\% do total da receita apurada anualmente. Esse percentual está bem próximo da média mundial calculada por Battal e Bakir (2017).

\subsection{Plano de aula sugerido}

Sugere-se a seguinte divisão do tempo para organização da aula (estudo de caso) supondo-se 110 minutos de duração:

\begin{tabular}{lc}
\hline Atividade & $\begin{array}{c}\text { Tempo } \\
\text { (minuto) }\end{array}$ \\
\hline 1. Apresentação da evolução do setor aeroportuário mundial & 30 \\
2. Apresentação e entendimento do caso em si & 15 \\
3. Cálculo do desequilíbrio financeiro/aeroporto & 20 \\
4. Cálculo da necessidade adicional futura de caixa/ano & 15 \\
5. Discussão do caso (professor/estudantes) & 20 \\
6. Fechamento da aula & 10 \\
\hline Total do tempo das atividades & 110 \\
\hline
\end{tabular}

Os estudantes devem fazer as atividades 3 e 4 sem a ajuda do professor. $O$ professor entra em cena na atividade 5. O professor antes deve ter apresentado as atividades 1 e 2. Para reforçar o aprendizado, o professor pode passar uma atividade extraclasse, como a sugerida a seguir.

\subsection{Para refletir}

Se a AFIT cobrasse $20 \%$ do valor de outorga na forma de downpayment (no ato da assinatura do contrato, equivalente ao valor de entrada), como ficaria o desequilíbrio financeiro acumulado em 2018 por cada aeroporto concedido e a necessidade adicional futura de caixa de cada aeroporto concedido de 2019 até o fim da concessão?

Essa atividade deve ser executada extraclasse e discutida nos quinze primeiros minutos da aula seguinte.

Os conceitos fundamentais e necessários para o desenvolvimento dessa atividade estão presentes na nota técnica preparada pelo especialista Marcus R. Fortes. Nessa situação, o valor de outorga a ser pago durante a vigência da concessão será equivalente a $80 \%$ do valor original, sem entrada. 


\section{Considerações finais}

O diretor Sebastian Fernandez, da Agência Federal de Infraestruturas de Transportes (AFIT) de um país fictício, desconfiava que os únicos dois aeroportos internacionais, concedidos em 2014, em breve estariam insolventes e que ingressariam na AFIT com pedido de relicitação. A Agência reconhecia que as infraestruturas aeroportuárias e os serviços prestados pelos aeroportos melhoraram significativamente após as concessões, haja vista os prêmios recebidos pelos dois aeroportos.

Um aeroporto localiza-se na capital do país e outro, na Região Sul. Após os investimentos planejados, a capacidade anual de movimentação de passageiros do aeroporto da capital passou para 5 milhões de passageiros em 2016, enquanto a capacidade do aeroporto do Sul subiu para de 3,5 milhões de passageiros por ano. O aeroporto da capital foi adquirido por uma empresa alemã de gestão e operação aeroportuária por $\$ 3,8$ bilhões e o aeroporto do Sul foi adquirido por uma empresa espanhola, que pagou $\$ 1,8$ bilhão. O prazo de concessão de ambos os aeroportos é de 30 anos, expirando no fim de 2043. Os dois aeroportos estão listados na bolsa local. O aeroporto da capital vendeu ações ordinárias e debêntures (obrigações) e o do Sul, somente ações ordinárias. O modelo de governança adotado pelos dois aeroportos privilegia os interesses de seus acionistas.

No dia 13 de agosto de 2019, o diretor Fernandez pediu para o especialista em regulação da Agência, Marcus R. Fortes, preparar um estudo, teoricamente embasado, que respondesse às duas seguintes perguntas: (a) qual o tamanho do desequilíbrio financeiro acumulado em 2018 por cada aeroporto concedido? e (b) qual a necessidade adicional futura de caixa de cada aeroporto concedido de 2019 até o fim da concessão?

No dia 22 de outubro do mesmo ano, precisamente às 10 horas, o especialista Marcus R. Fortes, acompanhado do seu chefe imediato, Dr. Jornada, encontrava-se no gabinete do diretor Fernandez para apresentar os resultados de seu estudo.

O estudo de Marcus fundamentou-se na matéria Engenharia Econômica, precisamente no conceito de lucro anual uniforme. Desse conceito, Marcus derivou o valor do desequilíbrio financeiro de cada aeroporto concedido e a necessidade adicional futura de caixa.

Marcus concluiu que o aeroporto da capital necessitará faturar, adicionalmente, \$16 milhões por ano para manter suas contas equilibradas daqui em diante, até o vencimento da concessão. A situação financeira do aeroporto do Sul é razoavelmente melhor: a sua necessidade adicional de recursos anuais até o fim da vigência da concessão é de $\$ 4,4$ milhões.

O diretor Fernandez pretende apresentar o estudo de Marcus na próxima reunião da diretoria da Agência. Ele solicitou ao Departamento Jurídico um parecer justificando uma possível renegociação do valor de outorga.

Nesse momento, a AFIT encontra-se elaborando o edital de concessão de seus principais portos marítimos. O edital deve ser lançado em meados de 2021. AAgência exigirá o pagamento de $20 \%$ do valor do lance vencedor no ato da assinatura do contrato de concessão. Com isso, pretende-se conter o entusiasmo dos concorrentes do leilão dos portos.

Finalmente, um estudo de caso que poderia ser derivado deste seria um que calculasse as quantidades de passageiros e de aeronaves necessárias para tornar as contas do aeroporto equilibradas. Para tanto, seriam necessários dados desagregados sobre tarifas por tipo de serviço prestado, receitas não voo, custos operacionais, despesas administrativas, entre outras, bem como a fixação de premissas sobre a participação relativa de cada serviço no total de serviços prestados.

\section{Referências}

AULICH, C. Airport privatisation in Australia: a tale of three cities. Applied Finance and Accounting, [S. I.], v. 1, n. 1, p. 1-11, 2015. DOI:10.11114/afa.v1i1.614.

BAIJAL, P. From nationalisation to privatisation: UK and Japan. Economic and Political Weekly, [S. I.], v. 35, n. 13, p. 1101-1106, Mar. 2000.

BEZERRA, G. C. L.; GOMES, C. F. Performance measurement in airport settings: a systematic literature review. Benchmarking An International Journal, [S. I.] v. 23, n. 4, p. 1-29, 2016. DOI: 10.1108/BIJ-10-2015-0099.

COSTA, L. H. G.; SANTOS, E.; NASCIMENTO, M. A.; SILVA, J. A. Análise da evolução dos modelos de participação privada nos aeroportos brasileiros. In: CONGRESSO NACIONAL DE PESQUISA EM TRANSPORTE DA ANPET, 31., 2017. Recife. Anais [...]. Recife: ANPET, p. 1-12, 2017.

FERREIRA, R. G. Engenharia econômica e avaliação de projetos de investimento. São Paulo: Atlas, 2009.

FINNERTY, J. D. Project financing: asset-based financial engineering. Hoboken, New Jersey: Wiley Finance, 2013. 
FLORIN, A.; KNÁPKOVÁ, A.; KRYEZIU, L.; BAGIS, M. Valuation of privatized companies in the transition economies: the case of Prishtina international airport. In: INTERNATIONAL SCIENTIFIC CONFERENCE FINANCE AND PERFORMANCE OF FIRMS IN SCIENCE, EDUCATION AND PRACTICE, 8., 2017, Zlín. Proceedings [...]. Zlín: Tomas Bata University, 2017. p. 16-29.

FORSYTH, P.; NIEMEIER, H.; WOLF, H. Airport alliances and mergers - Structural change in the airport industry? Journal of Air Transport Management, [S. I.], v. 17, n. 1, p. 49-56, 2011. DOI: 10.1016/j.jairtraman.2010.10.011.

GALEANA, O. A. R. The privatisation of Mexican airports. Journal of Air Transport Management, [S. I.], v. 14, n. 16, p. 320-323, 2008. DOI: 10.1016/j.jairtraman.2008.08.009.

GILLEN, D. The evolution of airport ownership and governance. Journal of Air Transport Management, [S. I.], v. 17, n. 1, 3-13, 2011. DOI: 10.1016/j.jairtraman.2010.10.003.

GRAHAM, A. The objectives and outcomes of airport privatization. Research in Transportation Business \& Management, [S. I.], v. 1, n. 1, p. 3-14, 2011. DOI: 10.1016/j.rtbm.2011.05.004.

GUPTA, R. Issues in airport infrastructure development under public private partnership. International Journal of Business and Management Invention, [S. I.], v. 4, n. 6, p. 66-77, 2015.

HOOPER, P. Privatization of airports in Asia. Journal of Air Transport Management, [S. I.], v. 8, n. 5, p. 289-300, 2002. DOI: 10.1016/S0969-6997(02)00009-1.

Jensen, M. Value maximization, stakeholder theory, and the corporate objective function. Journal of Applied Corporate Finance, [S. I.], v. 14, n. 3, p. 8-21, 2001. DOI: 10.2139/ssrn.220671.

JONES, C.; DUNSE, N. The valuation of an airport as a commercial enterprise. Journal of Property Investment and Finance, [S. I.], v. 33, n. 6, p. 574-585, 2015. DOI: 10.1108/JPIF-07-2015-0048.

JUAN, E. J. Privatizing airports: options and case studies. Washington: The Word Bank, 1996. (Viewpoint, 82).

MIECZNIKOWSKI, S.; TKOCZYŃSKI, D. Privatization of entities in the air transport sector - airports. Berlim: Spinger, 2018.

OLARIAGA, O. D.; ÁLVAREZ, J. A. Evolution of the airport and air transport industry in Colombia and its impact on the economy. Journal of Airline and Airport Management, [S. I.]v. 5, n. 1, p. 39-66, 2015. DOI: 10.3926/jairm.43.

OLARIAGA, O. D.; MORENO, L. P. Measurement of airport efficiency: the case of Colombia. Transport and Telecommunication Journal, [S. I.], v. 20, n. 1, p. 40-51, 2019. DOI: 10.2478/ttj-2019-0004.

PEREIRA, E. S.; ROCHA, C. H. Concessões aeroportuárias brasileiras, saúde financeira e prática regulatória: uma aplicação do modelo Fleuriet. Revista Estudos e Pesquisas em Administração, Mato Grosso, v. 3, n., p. 148-161, 2019. DOI: 10.30781/repad.v3i3.9011.

POOLE, R.; EDWARDS, C. Privatizing U.S. airports. Tax and Budget Bulletin, [S. I.], n. 76, p. 1-7, 2016.

VASIGH, B.; HARIRIAN, M. An empirical investigation of financial and operational efficiency of private versus public airports. Journal of Air Transportation, [S. I.], v. 8, n. 1, p. 91-110, 2003.

VASIGH, B.; OWENS, J. M.; YOO, K. E. A price forecasting model for predicting value of commercial airports: a case of three Korean airports. International Journal of Transport Management, [S. I.], v. 1, n. 4, p. 225-236, 2003. DOI: 10.1016/j.ijtm.2004.04.001.

YANG, X., TOK, S. K., \& SU, F. The privatization and commercialization of China's airports. Journal of Air Transport Management, [S. I.], v. 14, n. 5, p. 243-251, 2008. DOI: 10.1016/j.jairtraman.2008.04.012. 


\section{Contato:}

Carlos Henrique Rocha

E-mail: chrocha@unb.br

Paulo Augusto P. de Britto

E-mail: pbritto@unb.br 